\title{
PERCEPTION AND HEALTH RISK AWARENESS OF WHITEVERTISED SKINCARE PRODUCTS AMONG WOMEN IN ANAMBRA STATE, NIGERIA
}

\author{
Ogochukwu C. Ekwenchi \\ Nnamdi Azikiwe University, Awka \\ ogoekwenchi@yahoo.co.uk \\ Chinedu Richard Ononiwu \\ Nnamdi Azikiwe University, Awka \\ ononiwumartins@gmail.com
}

\begin{abstract}
'Whitevertised' skincare products are found in such societies as Nigeria where women show reverence for white skin. They are presented using a plethora of advertisement techniques that can make white skin appear desirable. Anchored on social constructionism and selective perception theory, this study aimed to find out how women in Anambra State perceive these products and their awareness of the health risks they can pose. To achieve these objectives, a quantitative approach involving survey was adopted. Data were collected from a random sample of 400 women. Findings showed that these products are prevalent and are used by most of the respondents to 'maintain' their skin colour. The study also showed that the perception towards these products varied with age and educational qualification, and was also shown to be influenced by price, place of origin, scientification, celebrityendorsements and past experiences. In addition, findings from the study showed that the health risk awareness of the risks these products can pose was low among the younger respondents and the least educated. Based on these findings, this study recommended health awareness campaigns targeted at the young and least educated who were shown in this study as most vulnerable.
\end{abstract}

Keywords: Perception, health risk awareness, whitevertising, whitening, skincare products

\section{INTRODUCTION}

'Whitevertised', coined by the fusion of 'white' and 'advertised', describes skin whitening products that have been advertised in such ways that their whitening effects are highlighted and as well made to appear desirable. These products are prevalent in such societies found to have high regards for skin 'whiteness'. In these societies, the definition of female beauty is so narrow that a woman must have 'white skin' before she is deemed beautiful (Leong, 2006). 'Whitevertised' skincare products are, therefore, the advertiser's subtle means of reminding women that there exists a beauty standard that they must meet to be accepted as beautiful. On these skincare products are as well the advertiser's promise to the women that they can be helped to attain this skin colour.

Since advertisement has the potential to mould individual's actions and reactions and create acceptance for products in their minds (Saeed, Naseer, Haider, \&Naz, 2014), the techniques employed by advertisers of whitening skincare products are capable of persuading 'women of colour' to desire to have a 'whiter skin' and to have positive perception toward the 'whitevertised' skincare products, which may lead to purchase and eventual use. However, behind these glittery promises and techniques lie such health risks as kidney damage which these products can pose (Murphy, Kim, Chanra, Lim, Wilson, Irvine, Slotton \& Allen,2015) due to such chemicals like steroids and hydroquinone which are sometimes used in their formulation (Olumide, Akinkugbe, Altraide, Mohammed, Ahamefule\&Ayanlowo, 2008). 
Therefore, danger lurks if women who use these products or intend to use them, are not aware of this fact. It is against this backdrop that this study examined how women in Anambra State, Nigeria perceived 'whitevertised' skincare products and their level of awareness on the risks they can pose. This was with the view to finding out how susceptible the women are to the persuasiveness of advertisements on these products.

Anambra State was selected because it is home to what has been named the largest market in West Africa-the Onitsha Main Market (Ibenegbu, 2018). There are many importers especially of cosmetics, clothes, and shoes in the market, making it a haven for all sorts of products that have been advertised using a plethora of gimmicks. 'Whitevertised' skincare products, as the researchers found, are one of such that can be found in Onitsha Main Market in large quantities, from where they are distributed to different parts of Anambra State.

This study is significant as it would seem that most of the studies on the use of whitening skincare products have focused on their health risks (see Olumide et al.,2008; Murphy et al.,2015) with few focusing on the health risk awareness and perception of these products (especially those advertised as whitening) in such countries as Nigeria where WHO (2011) has found that women use them avidly. It adds to the existing literature on audience/ consumer reception and perception of advertisement. It also adds to the existing body of literature on the effects of the 'white beauty' hegemony on African women and literature on perception and health risk awareness on whitening skincare products. In addition, it would help the bodies involved in the regulation of advertising in Nigeria in the formulation of policies on the advertisement of cosmetics. If found that some women can develop a positive perception towards whitening skincare products that can be harmful to them, due to the plethora of tricks the advertisers employ in their advertisements, such ads and products as well can be banned. Findings from this study can also guide such bodies as NAFDAC who can sensitize citizens on the dangers of using some whitening skincare products. Besides, identifying the category of women who have a positive perception towards 'whitevertised' skincare products can be crucial in developing and targeting messages to dissuade them from buying and using these products.

\section{STATEMENT OF THE PROBLEM}

Skin bleaching which refers to the application of some cosmetics in an attempt to de-pigment or lighten the skin complexion is increasingly becoming the norm (Charles, 2003; WHO, 2011; McDougall, 2013). Although the use of skin whitening (bleaching) products is global, African women are shown to be some of their biggest consumers (Street, Gaska\& Lewis \& Wilson, 2014). Whitening skincare products can present such health risks as kidney damage (International Programme on Chemical Safety, 2003), skin rashes, skin discolouration, scarring, bacterial and fungal infections, psychosis, and peripheral neuropathy (UNEP, 2008; Ladizinki, Mistry\&Kundu, 2011). It is therefore worrisome if a segment of the population of any country is seen to favour the use of such products, hence the need to find out how much they are aware of the health risk and raise the alarm when the health risk awareness is low. The high rate (Etcoff, Orbach, Scott \& D' Agostino, 2004) and ways these products are advertised are also a source of concern as manufacturers employ some tricks in their bid to enhance sales. For example, cosmetic companies may use such expressions as "fine fairness" (Leong, 2006) which may lure potential consumers.

The Nigerian woman's seeming craze for "whiter skin" (Adow, 2013), the rate at which she uses whitening skincare products (WHO, 2011), the possibility that the advertisers of thes 
DOI: doi.org/10.47851/naujocommed.v2i1.117

products have aided practice, and the possibility that this high rate does not correlate with a high level of health risk awareness inspired this study. The level at which Nigerian cosmetic markets brim with skincare products highlighting their whitening effects and their promise of a desirable skin colour also aroused the researchers' curiosity regarding the perception (both of risk) consumers may have of these products and the impact of persuasive advertising on their purchase decision.

In addition, it seems that the high rate at which these products are used does not correspond with the number of research findings on how they are perceived and the proportion of users who are aware of the health risks they can pose. Given the highlighted problem, this study explored how women in Anambra State perceive 'whitevertised' skincare products and factors that can influence perception, in addition to the proportion that are aware of the health risks these products can pose. In precise terms, the study was aimed at the following:

1. To determine the perception of 'whitevertised' skincare products among women in Anambra State;

2. To determine the factors that can influence the perception of women in Anambra State toward 'whitevertised' skincare products.

3. To ascertain the proportion of women in Anambra State who actively seek out 'whitevertised' skincare products and why;

4. To investigate the extent to which women in Anambra State are aware of the health risks of 'whitevertised' skincare products.

5. To find out the main source of health risk awareness on 'whitevertised' skincare products.

\section{LITERATUREREVIEW}

\section{Consumer perception of body care products}

Studies have identified consumers' perception of body care products generally. One of these studies was conducted by TNS Opinion \& Social (2009) to find out the perception of sunscreen in Europe. Findings showed that only $16 \%$ of Europeans believe that sunscreen contains harmful chemicals. In-line with this, when asked about the risk sunscreen poses to people within their country, only $16 \%$ classify sunscreen as risky while the majority of Europeans classify sunscreen as not risky (59\%). The remaining $10 \%$ of respondents are undecided on the matter. Regarding age and risk perception, findings from the study conducted by TNS Opinion \& Social showed that the younger the respondents, the more likely they were to classify sunscreen as not risky to both people in general and themselves personally, and the more likely they are not to worry about the potential risk inherent in sunscreen. On their part, Muise and Desmarais (2010) conducted a study among 304 Canadian women who ranged in age from 19 to 73 to explore their perceptions of anti-aging products and found that although one major reason for using or to consider using anti-aging products was to maintain a youthful appearance, only $3 \%$ of the participants felt that these products worked well.

Thanisorn, Byaporn and Chanchai (2012) conducted a study to investigate the factors that influenced the perception of Thai consumers on facial herbal cosmetic products (moisturizer, whitening lotions, creams, powder, toner, make up cleansing, mask, cleansing, oil, soap bar, anti-aging lotions and creams) in Thailand. Findings from the research showed that Thai consumers were satisfied with physical appearance of the products; texture, odour, penetration, characteristics and viscosity. In addition, findings showed that they 
DOI: doi.org/10.47851/naujocommed.v2i1.117

satisfied with the advertisement of the products; brochure, leaflet, beauty information from general magazine, fashion magazine, general book, television and radio. Similarly, research conducted by Santoso and Raharjo (2013) found that respondents had a positive perception of skincare products. The respondents perceived the products as safe to use. They were of the view that the products had a positive effect on their skin and could make them feel more confident about themselves. Regarding country of origin, respondents perceived the UK to produce high-quality natural skin care products, while Germany was perceived to make highquality organic skin care products. Respondents view the USA as the least that produces good quality natural skincare products, while South Korea was perceived as the least country that produces high-quality organic skin care products.

Regarding risk perception, Yoo and Kim (2012) conducted a study to explore consumer riskperceptions and body satisfaction in relation to tanning product consumption. To collect the data for this study, 59 male and 208 female college students were surveyed using a selfadministered online survey tool. The study revealed that consumers were concerned with the quality of a tan, especially the color, achieved through sunless lotions or creams. Findings from the study also showed that tanned colour is desired by the individuals and it directly concerns social risk in terms of how their skin looks to others.

\section{Health risk awareness of skin whitening products}

The health risk awareness of skin whitening products has also been a focus of research. To access the knowledge, attitudes and practices of women regarding skin-lightening products and to quantify the potentially harmful substances in the products, Cristaudo, D'ilio, Gallinella, Mosca, Majovani, Violante, Senofonte, Marrrone and Petrucci (2013) conducted a cross-sectional study among 82 non-Italian women. The respondents were visiting an outpatient facility in Rome, Italy. Findings from the study showed that out of the 82 women, 33 used skin-lightening products and just one -fourth of these women were aware of the potential risks. The researchers concluded that consumers must be informed of the potential risks in using skin-lightening products.

Similarly, Kuffour, Dartey, Owusu and Dabouh (2014) found in a study involving 120 women in the Bolgatanga municipality of Ghana that $39.2 \%$ of them made use of cosmetic bleaching products; $7.5 \%$ experienced related side effects, and $82.4 \%$ did not know the side effects of the bleaching products. Darj, Infanti, Ahlberg and Okumu (2015) also found in a study conducted in Sweden, involving 455 pregnant women, that the participants had little knowledge about the contents or ingredients in skin bleaching products and potential side effects including potential transmission through the placenta with effects to the foetus. Results from the study also showed that other pregnant women disagreed that bleaching skincare products had any negative side effects or did not consider them significant.

Literature shows that women go for whitening skincare products and are unaware of their potential side effects. However, none of the studies reviewed focused on the perception of skincare products advertised as whitening. None of the studies also focused on the extent to which women go for skincare products advertised as whitening and why. There also seems to be a paucity of findings on the factors that can influence the perception of these products. In addition, though there are findings on the level of health risk awareness on whitening skincare products, there seems to be a paucity of research specifically on skincare products advertised as whitening. Research findings on the sources of health risk awareness on 
DOI: doi.org/10.47851/naujocommed.v2i1.117

whitening skincare products and such advertised as whitening also seem lacking. The studies reviewed are also mainly foreign-there seems to be a paucity of Nigerian studies related to this study. This is an important gap in literature given the high rate at which Nigerian women go for whitening skincare products according to WHO (2011). These gaps in literature are what this study aims to fill.

\section{THEORETICAL FRAMEWORK}

Two theories were considered to explain how the society (including the media as part of the society) constructs reality and how individuals in the society can react to these constructs. These are social constructivism and selective perception theory.

\section{Social Constructionism}

According to McQuail (2010), social constructionism is an abstract term for a very broad and influential tendency in the social sciences, sparked off especially by the publication of Berger and Luckman's book "The Social Construction of Reality" in 1967. For McQuail, social construction refers to the processes by which events, persons, values and ideas are first defined or interpreted in a certain way and given value and priority, mainly by mass media, leading to the (personal) construction of larger pictures of reality.

Going by the propositions of social constructionism, the media provides such materials as 'pale beauty models' used in the construction of a beauty standard. This normative female ideal image is the image against which consumers of skin whitening must measure themselves and may ultimately fail to meet. However, the meanings offered by the media concerning "whiteness" as part of a globalized beauty standard can either be negotiated or out-rightly rejected because the audience is active. Though the power of the media to construct reality is evident, the society can be considered too fluid for the media to absolutely manipulate. There are such factors as biological influences and culture that can determine individuals' understanding and behaviour (Sokal\&Bricmont, 1999). Individuals' level of education, age, marital status, occupation and place of residence can also be added to this list of determining factors. These may make individuals reject whatever the media presents to them as reality. In fact, according to McQuail (2010), social constructionism has it in one of its prepositions that though meanings are offered by the media, they can either be negotiated or rejected.

\section{Selective Perception}

The evidence of selective perception in media studies suggests that individuals can consciously or unconsciously view aspects of information so that it favours them at the expense of those viewed as distracting, unimportant or insignificant. This evidence shows a heterogeneous media audience, who belong to different socio-economic strata, perceiving the same message differently, according to their disposition. Due to the tendency of the audience to have diverse perceptions after exposure to the same type of messages, women in Anambra State, Nigeria are likely to have different perceptions towards skincare products advertised as whitening. These perceptions may vary with such demographic variables as age and educational qualification.

The selective perception theory does well to explain why individuals, after exposure to the same kind of messages, cannot toe the same line of perception. Anaeto, Onabajo and Osifeso (2008) write that selective perception is the tendency for people's perception to be influenced by wants, needs, attitudes and other psychological factors. This means that different people can react to the same message in different ways. Okunna and Omenugha (2012) believe tha 
DOI: doi.org/10.47851/naujocommed.v2i1.117

when people are exposed to mass media messages, they tend to interpret them to suit their existing attitudes, preconceptions, and predispositions. However, while the argument that the audience can cushion the direct effect of the media by way of selective perception holds water, it may have underestimated the power of the media. The selective perception theory may have overlooked the possibility that some media messages may be so persuasive that they can sway the audience no matter their perception. In this case, selective perception amounts to little or nothing. It, therefore, becomes a question of what happens after the selective perception. The research evidence that some women can have negative perception toward some skincare products and go on to use them (Muise\&Desmarais, 2010) is an indication that selective perception is not all that matters.

\section{METHODOLOGY}

The study was designed as a survey. The study population was the total number of women in Anambra State. The number is2, 059, 844, according to the National Population Commission in figures released after the 2006 population census (NPC, 2006).

\section{Sample size and sampling procedure}

This study adopted a statistical model initiated by Taro Yamane to determine the sample size of this study thus:

The formula is:

$$
\begin{aligned}
& =\frac{n}{1+N(e)^{2}} \\
& \text { When } \mathrm{n}=\text { Sample size } \\
& \mathrm{N}=\text { Population size } \\
& \mathrm{E}=\text { degree of tolerable error } \\
& \mathrm{I}=\text { Constant }
\end{aligned}
$$

Applying the formula and allowing 5\% error margin, we have:

$$
\begin{aligned}
& \mathrm{N}=\frac{2,059,844}{1+2,059,844(0.05)^{2}} \\
& \mathrm{n}=\frac{2,059,844}{1+2,059,844(0.0025)} \\
& 1+(2,059,844 \times 0.0025) \\
& 1+5,149.61 \\
& =5,150.61
\end{aligned}
$$

$$
\begin{aligned}
& \mathrm{n}=\frac{2,059,844}{5,150.61} \\
& =399.9
\end{aligned}
$$

This figure was approximated to 400 .

A multi-stage procedure was employed for sample selection. The first stage involved the random selection of two senatorial districts: Anambra Central and Anambra South, while the second stage involved the selection of two local government areas from each of the senatorial zones as follows: Anambra Central- Awka North and Idemmili North; and Anambra SouthOrumba South and Nnewi South. At the third stage, the researchers selected two towns from each of the four local government areas using a 'lucky dip' process. This gave a total of eight (8) towns (four urban and four rural). The fourth stage involved the selection of streets/quarters/villages using a table of random numbers. Four streets/quarters (as the case may be) were selected from each of the urban communities, while four villages were selected from the rural communities. 
At the fifth stage, the researchers randomly selected 216 households. The households were the 184 where two (2) available and willing women aged 18 and above, and 32 where one (1) available and willing woman of the same age bracket were found. To reduce bias, the starting point for each street/quarter/village was selected randomly, using a 'lucky dip' process. Landmarks (signposts, tallest buildings, etc.) in the streets/quarters/villages were written in pieces of paper which were then folded. Any picked landmark served as a starting point for each street/quarter/village. The sample from each Local Government Area was drawn according to their population. Furthermore, the sampling interval was determined by dividing the sample size (400) by the total number of households to be sampled (216). This gave 1.8 (approximately 2). Thus, a household was skipped to get to the one to be sampled (the $2^{\text {nd }}$ household).

The instrument used for the data collection for the survey was a 36-item questionnaire. The items addressed the variables related to the research questions developed for this study and were structured in a close-ended form. Copies of the questionnaire were administered face-toface by trained research assistants and the researchers. The assistants were trained before the actual take-off of fieldwork. They were informed about the research and how to get to the respondents. They were employed during the pre-test exercise to assess their efficiency and reliability for the actual fieldwork.

\section{FINDINGS AND ANALYSIS}

Demographic variables

With regard to the respondents' highest educational qualification, 30.5\% $(n=122)$ stated that they had a Senior School Certificate (SSCE) or its equivalent, followed by those who stated that they had First School Leaving Certificate (29.5\%; n=118), First Degree/HND (23.3\%; $n=93)$, and Postgraduate degrees $(8.8 \% ; n=35)$. Only $2.5 \%$ of the respondents stated that they had no formal education. This result suggests that most of the respondents have basic education and can therefore read and understand the English words used on 'whitevertised' skincare products.

\section{Respondents' perception of 'whitevertised' skincare products}

This section presents results on the respondents' perception of 'whitevertised' skincare products. The section starts with the presentation of data on respondents' exposure and recognition of 'whitevertised' skincare products. The majority of the respondents $(95 \%$; $\mathrm{n}=380$ ) stated that they were exposed to advertisements for skin whitening products. This result suggests that women have been bombarded with advertisements for skin whitening products. This is consistent with the assertions of Zhang (2013) and Sylvia (2014) that such advertisements can be seen everywhere. Furthermore, data showed that $46.8 \%$ of the respondents recognized 'whitevertised' skincare products by the skin colour of the model presented, while $36.8 \%$ recognized them by their names. In addition, $11.5 \%$ recognized them by the words used in the advertisement. This result suggests that the models and their skin colour are perhaps the most conspicuous in the advertising of skin whitening products.

Results showed that majority of the women (92\%) were of the perception that majority of the skin whitening products would produce a whitening effect. However, there was a far smaller percentage $(6 \%)$ of women who were of the perception that few 'whitevertised' skincare products would produce a whitening effect. This category of respondents could be likened to those found in the study conducted by Muise and Desmarais (2010) who saw skin whitening products as gimmicky, questioning their effectiveness. Muise and Desmarais' study 
DOI: doi.org/10.47851/naujocommed.v2i1.117

showed these two classes of women- one who perceived that whitening skincare products would produce a whitening effect and another who saw such products as gimmicky, questioning their effectiveness.

Additionally, results showed that most of the respondents (62\%) perceived majority of the 'whitevertised' skincare products as desirable. These products perceived so may be the ones they have used to achieve the desired whitening effect or whose advertisements may have influenced their perception. The $14 \%$ who perceived few as desirable may have such perception for the few they have used and the $20 \%$ that perceived none as desirable may be those who frown against 'whitevertised' skincare products.

Results also showed that the number of respondents who perceived majority of the 'whitevertised' skincare products as safe $(48.5 \%)$ were more than those who perceived all, few and none of them as safe $-1 \%, 34.3 \%$ and $16.3 \%$, respectively. A varied perception of safety was also shown in the study by TNS Opinion \& Social (2009). The perception of all and the majority of these products as safe may be due to past experience or influence of advertisements. The perception of few and none of these products as safe may as well be due to past experience or high level of risk awareness.

\section{Factors that can influence the perception of 'whitevertised' skincare products}

This study explored some factors that are likely to influence the perception of 'whitevertised' skincare products as shown in literature. They include the place of origin of the product (whether foreign or Nigerian-made), the use of celebrities in advertising, 'scientification', price and past experience. Data showed that the percentage of respondents who perceived majority of the foreign 'whitevertised' skincare products as safe $(40.5 \%)$ were more than those who perceived all (13.0\%), few (33.3\%), and none of them as safe (13.3\%). Findings from this study also showed that most of the respondents $(66.5 \%)$ perceived few Nigerianmade 'whitevertised' skincare products as safe. This result suggests that more respondents perceived foreign-made 'whitevertised' skincare products as safer than those made in Nigeria.

More so, findings from this study showed that the majority of the respondents $(55.3 \%)$ perceived the use of celebrities in an advertisement as meaning good quality, while $38.3 \%$ stated otherwise. This result suggests that the respondents who perceived the use of celebrities in an advertisement as meaning good quality have positive perception towards these products and this can elicit a purchase and use behavior favourable to the manufacturers. This finding is consistent with that of Ahmed et al. (2015) who found that celebrity endorsement in advertisements elicits positive responses from consumers.

Furthermore, the percentage of respondents who perceived the 'scientifically tested' claim as meaning that the product is safe $(42.3 \%)$ was more than those that stated that it does not mean so $(35.3 \%)$. This result suggests that the respondents who were of the view that the 'scientifically tested' claim means that a 'whitevertised' skincare product is safe are likely to fall prey for 'scientification' of skin whitening products as Mire (2005) describes it. More so, majority of the respondents $(56.8 \%)$ perceived high price of these products as meaning high quality most of the time. In addition, findings from the study showed the percentage of respondents who perceived these products as unsafe after an experience of side effects $(43 \%)$ were more than those that perceived it as safe after the same experience (4.5\%). The percentage of respondents who gave 'no answer' (52\%) are perhaps those who have n 
DOI: doi.org/10.47851/naujocommed.v2i1.117

experienced a side effect after the use of 'whitevertised' skincare products or those who have not used them at all. This result confirmed that experience of side effects is a factor that can influence perception since more respondents who have experienced side effects after the use of these products are likely to perceive them as unsafe.

Interestingly, findings from this study showed that perception could vary with age and education. With regard to that of safety, for example, the younger respondents seemed to throw caution to the wind, while the older ones held theirs close. Most of respondents aged 18-24 perceived some 'whitevertised' skincare products as safe- 112 out of $163(68.7 \%)$ and only 20 out of 163 of them so perceived none of these products. On the other hand, most of the respondents aged 40 and above perceived none of the 'whitevertised' skincare products as safe (19 out of 70) and none perceived all as safe. This result showing a seeming carefreeness among the younger respondents towards safety is not strange; TNS Opinion \& Social (2009) found the same result. 'Young, wild and free' explains the adventurousness of the younger ones, which can make them overlook safety issues. They may not see the risk inherent in 'whitevertised' skincare products until they fall prey.

With regard to education and safety perception, only 2 out of the respondents with no formal education and the same number with First School leaving Certificate perceived all 'whitevertised' skincare products as safe. This suggests a sort of carelessness among respondents with little or no education. However, only $12.9 \%$ of respondents with first degree/ HND perceived none of these products as safe. This result suggests that respondents with first degree/ HND can also be careless about the risk of 'whitevertised' skincare products. The responses on factors that can influence perception toward 'whitevertised' skincare products helped to further probe the respondents' stance on these products. In fact, some of the women seemed to contradict themselves when they responded that there was no safety in 'whitevertised' skincare products and at the same time gave responses that suggest they could go for some instead of the others- for example, the foreign-made and expensive products.

\section{Respondents' search, use, and purchase of 'whitevertised' skincare products}

Data on the proportion of respondents that have searched for 'whitevertised' skincare products showed that majority of the respondents (50.8\%) stated that they have never searched for a 'whitevertised' skincare products at cosmetics shops, markets, and online. However, the difference between this figure and that of those that stated they have done so (49.2\%) is not significant. Also, data showed that $47.3 \%$ of respondents stated that they have never desired to use 'whitevertised' skincare products. This result is somewhat contrasting from WHO (2011) statistics which showed that $77 \%$ of Nigeria women use whitening skincare products. However, it is important to mention the possibility that some of the respondents who stated they have never desired to use 'whitevertised' skincare products may have done so.

Furthermore, data showed that majority of the respondents have purchased these products $(75.5 \%)$. This figure does not correspond with that of those who have never desired to use them (47.3\%), meaning that some of the respondents may have purchased these products by accident. This result on the percentage of respondents that have purchased a 'whitevertised' skincare product suggests that these products are readily available for sales, so much that even those who have not searched for them or desire to use them can purchase them accidentally. 
More so, results showed that the percentage of respondents who would choose a 'whitevertised' skincare product over a 'non- whitevertised' most of the time $(25 \%)$ was more than those who would choose it all the time and rarely who are $17.3 \%$ and $12 \%$, respectively. However, $20.8 \%$ have bought these products accidentally and this gives credence to the assumption that some of them may have purchased by accident. This result suggests that a greater number of respondents have been influenced by the various gimmicks employed in the advertising of whitening skincare products. For the respondents' reason for purchasing these products, the percentage who purchased them to maintain their fair skin (20\%) was more than those who did so to have fairer skin and change skin colour who were $15 \%$ and $13.8 \%$, respectively. This result suggests that the use of 'whitevertised' skincare products is purpose-driven. What these results suggest is a reverence and love for white skin as Liley, 2001 and Arif (2004) would put it. For those of them who described their skin colour as 'light' and also stated that the used 'whitevertised' skincare products to have fairer skin, this love becomes even more glaring.

\section{Health risk awareness of 'whitevertised' skincare products}

This section presents data on the health risk awareness of 'whitevertised' skincare products. The study focused on the awareness of the health risk of Diabetes Mellitus, Skin scarring, fungi and bacteria infections, menstrual irregularities, 'fish odour syndrome', skin discoloration, kidney damage, and complications that can lead to death. The awareness of the possibility that the skincare products can contain such harmful chemicals as mercury, hydroquinone and corticosteroids was also a focus of the study.

Table 1: Respondents' Awareness of Possible Health Hazards of 'Whitevertised' Skincare Products

\begin{tabular}{lllllllll}
\hline & $\begin{array}{l}\text { Diabetes } \\
\text { mellitus }\end{array}$ & $\begin{array}{l}\text { Skin } \\
\text { discoloration }\end{array}$ & $\begin{array}{l}\text { Skin } \\
\text { scarring }\end{array}$ & $\begin{array}{l}\text { Bacterial// } \\
\text { fungal } \\
\text { infections }\end{array}$ & $\begin{array}{l}\text { Menstrual } \\
\text { irregularitie } \\
\text { s }\end{array}$ & $\begin{array}{l}\text { Kidney } \\
\text { damage }\end{array}$ & $\begin{array}{l}\text { 'Fish odor } \\
\text { syndrome' }\end{array}$ & Death \\
\hline True & $4.5 \%$ & $78.8 \%$ & $55.3 \%$ & $32.8 \%$ & $9.3 \%$ & $9.3 \%$ & $34.3 \%$ & $3.5 \%$ \\
& $\mathrm{~N}=18$ & $\mathrm{~N}=315$ & $\mathrm{~N}=221$ & $\mathrm{~N}=131$ & $\mathrm{~N}=37$ & $\mathrm{~N}=37$ & $\mathrm{~N}=137$ & $\mathrm{~N}=14$ \\
False & $18.3 \%$ & $0 \%$ & $3.3 \%$ & $13.8 \%$ & $16.8 \%$ & $17.3 \%$ & $13.3 \%$ & $18.3 \%$ \\
& $\mathrm{~N}=7$ & $\mathrm{~N}=0$ & $\mathrm{~N}=13$ & $\mathrm{~N}=55$ & $\mathrm{~N}=67$ & $\mathrm{~N}=69$ & $\mathrm{~N}=53$ & $\mathrm{~N}=73$ \\
Not & $77.3 \%$ & $21.3 \%$ & $41.5 \%$ & $53.5 \%$ & $74 \%$ & $73.5 \%$ & $52.5 \%$ & $78.3 \%$ \\
Aware & $\mathrm{N}=309$ & $\mathrm{~N}=85$ & $\mathrm{~N}=166$ & $\mathrm{~N}=214$ & $\mathrm{~N}=296$ & $\mathrm{~N}=294$ & $\mathrm{~N}=210$ & $\mathrm{~N}=313$ \\
\hline Total & $100 \%$ & $100 \%$ & $100 \%$ & $100 \%$ & $100 \%$ & $100 \%$ & $100 \%$ & $100 \%$ \\
& $\mathrm{n}=400$ & $\mathrm{n}=400$ & $\mathrm{n}=400$ & $\mathrm{n}=400$ & $\mathrm{n}=400$ & $\mathrm{n}=400$ & $\mathrm{n}=400$ & $\mathrm{n}=400$ \\
\hline
\end{tabular}

As shown in Table 1, majority of the respondents (77.3\%) were not aware that 'whitevertised' skincare products could lead to Diabetes Mellitus. This result was not surprising because it is not a disease commonly associated with skincare products in this part of the world. It may have taken the versatility of $4.5 \%$ of the respondents to be aware that skincare products containing steroids could expose one to the risk of diabetes mellitus. However, majority of them $(78.8 \%)$ were aware that these products could cause skin discoloration. Furthermore, Table 1 showed that menstrual irregularity was one other health risk of 'whitevertised' skincare products the respondents showed little awareness of; only 9.3\% were aware that these products could cause menstrual irregularities. This was not surprising as this health issue, like diabetes mellitus, is not commonly associated 
DOI: doi.org/10.47851/naujocommed.v2i1.117

skincare products. Table 1 also showed that most of the respondents (73.5\%) were also unaware that 'whitevertised' skincare products could lead to kidney damage.

The awareness that complications from the use of 'whitevertised' skincare products can lead to death was lowest among the other health risks mentioned above. Only $3.5 \%$ of the respondents were aware that complications resulting from the use of 'whitevertised' skincare products could lead to death. This result was not surprising because such awareness may not come by without in-depth research. The respondents who show doubt in the possibility of 'whitevertised' skincare products leading to death by giving 'false' answer, were more than those who did so with regards to skin discoloration, kidney damage, menstrual irregularities, diabetes mellitus and fungi/bacterial infections.

Table 2: Respondents' Awareness of Potentially Hazardous Contents of 'Whitevertised' Skincare Products

\begin{tabular}{llll}
\hline & Mercury & Hydroquinone & Corticosteroids \\
\hline True & $26.5 \%$ & $45.3 \%$ & $13 \%$ \\
& $\mathrm{~N}=106$ & $\mathrm{~N}=181$ & $\mathrm{~N}=52$ \\
False & $4.8 \%$ & $0 \%$ & $0 \%$ \\
\multirow{3}{*}{ Not Aware } & $\mathrm{N}=19$ & $\mathrm{~N}=0$ & $\mathrm{~N}=0$ \\
& $68.8 \%$ & $54.8 \%$ & $87 \%$ \\
& $\mathrm{~N}=275$ & $\mathrm{~N}=219$ & $\mathrm{~N}=348$ \\
\hline \multirow{2}{*}{ Total } & $100 \%$ & $100 \%$ & $100 \%$ \\
& $\mathrm{~N}=400$ & $\mathrm{~N}=400$ & $\mathrm{~N}=400$ \\
\hline
\end{tabular}

Next, Table 2 presents data on the respondents' awareness of the possibility that 'whitevertised' skincare products may contain such harmful chemicals as mercury, hydroquinone and corticosteroids. As shown in the table, majority of the respondents $(68.8 \%)$ stated that they were unaware $(68.8 \%)$ that these products could contain mercury. Though hydroquinone is a common ingredient used in 'whitevertised' skincare products, Table 2 showed that majority of the respondents $(54.8 \%)$ were also unaware. While this may be due to lack of information about the content of 'whitevertised' skincare products, some of the respondents who may care to know or be aware may have seen other names like: 4Benzenediol, Quinol, Benzene-1, 4-diol, p-Diphenol, p-Dihydroxyl benzene, Hydrochinone, p-hydroxylphenol, Hydrochinonium, Hydroquinol, and Tequino according to Olumide et al. (2008). The table also showed that majority of the respondents $(87 \%)$ were unaware that 'whitevertised' skincare products could contain corticosteroids.

Table 3: Respondents' Level of Health Risk Awareness of 'Whitevertised' Skincare Products

\begin{tabular}{lll}
\hline & Frequency & Percent \\
\hline High Awareness & 37 & $9.3 \%$ \\
Average Awareness & 112 & $28.0 \%$ \\
Low Awareness & 251 & $62.8 \%$ \\
\hline Total & 400 & 100.0 \\
\hline
\end{tabular}

Table 3 presents data on the respondents' level of health risk awareness which was gotten by calculating the 'true' answers of the respondents. As shown in the table, the majority of the respondents $(62.8 \%)$ had a low level of health risk awareness of 'whitevertised' skincare products. This was followed by those who had average awareness (28\%). The least percentage was those who had high awareness $(9.3 \%)$. This result was similar to that of Cristaudo et al. (2013); Kuffour et al. (2014) and Darj et al. (2015) who found that women 
DOI: doi.org/10.47851/naujocommed.v2i1.117

showed a low level of awareness on the health risks whitening skincare products could pose. The implication of this result is that majority of the respondents would be susceptible to the risks that can be posed by 'whitevertised' skincare products since they are unaware of the diseases can cause and the dangerous chemicals that can be used in their formulation.

Regarding the major sources of health risk awareness, the percentage of respondents who stated 'friends and family' as their main source of health risk awareness of 'whitevertised' skincare products $(46.5 \%)$ was more than those that stated other sources- it was Internet for $15 \%$, television for $7.5 \%$, magazine for $3.7 \%$, radio for $2.5 \%$, newspaper for $2 \%$, and health journals for $1 \%$ of the respondents. However, $18.5 \%$ of them stated that they had no source of health risk awareness of whitening skincare products. The implication of this result is that many of the respondents are likely to be exposed to inaccurate health information, especially when their friends and family are not health professionals.

However, interestingly, findings from this study also showed that health risk awareness of 'whitevertised' skincare products varied with age. The respondents who had high awareness of the health risks posed by 'whitevertised' skincare products were most among those who fell within 25-30 years. Out of 91 of them, 23 (25.2\%) showed high awareness. Only 2 out of $163(1.22 \%)$ of the respondents aged 18-24 years showed high level of awareness. In addition, most of the respondents aged 18-24 showed low awareness of the health risks of 'whitevertised' skincare products- 130 out of 163 (79.7\%). This was followed by 55 out of 76 (72.3\%) of those aged 31-39. Only 23 out of 70 of the respondents aged 40 and above show low awareness. Interestingly also, health risk awareness also varied with education as $80 \%$ of the respondents with no formal education showed low awareness of potential health risk of 'whitevertised' skincare products, followed by $76.2 \%$ of those with First School Leaving Certificate. However, no respondent with a postgraduate degree had low awareness.

\section{DISCUSSION OF FINDINGS}

One major factor that seems to strengthen the white beauty hegemony nowadays is the marketing of beauty standards through the mass media. The findings of this study suggest that a beauty standard which has whiteness as part of it has been advertised on television, magazines, the Internet, billboards and the packaging or label of skin whitening products. These findings are substantiated by the assertions of Zhang (2013) and Sylvia (2014) that such adverts can be seen everywhere.

Findings from this study also revealed that 'whitevertised' skincare products can easily be identified by the 'white-skinned' models on them. This tells of a society with profound reverence for skin whitening. Simply put, the advertisement for whitening skincare products, and the products that have been so advertised, are reflections of the needs of a society. As De Cort (2009) notes, pale-skinned models are found in advertisements in Malaysia for instance, because its women want such skin colour. This seems typical of Nigeria. Nigerian women seem to find attractive the fair-skinned, spotless models presented in advertisements for whitening skincare products and the media generally. They also seem to be under a societal pressure to have flawless skin- a fair one preferably and one needed to be successful in such a society that revers such skin colour. This is perhaps the reason why some of them seek products to 'enhance' their skin with whitening skincare products.

The women who do not revere white skin are likely to be under some pressure to accept it as superior or ideal due to the various ways the media, through advertisements, portray 11 
DOI: doi.org/10.47851/naujocommed.v2i1.117

However, after the advertisement of these products, and their availability, comes perception. 'Whiteverised' skincare products, as shown in this study, are perceived in different ways. The various ways they are perceived- whether positively or negatively- suggest that the audience are active. When advertisers present these products to them, the advert claims are not taken hook, line and sinker, despite any technique employed. In fact, the finesse in the advert techniques can make women suspicious and begin to ask questions regarding how realistic the claims are. They may seem too gimmicky to be true.

Also, there is the likelihood that those who perceive these products as unsafe will avoid them, while those who perceive them as safe will have no worries making use of them. In a similar vein, those who perceive a few of these products as safe are likely to patronize the few so perceived and avoid the rest. It would indeed be bizarre to find one who perceives all 'whitevertised' skincare products as unsafe and go on to use any. However, if there are women who question the effectiveness of some skincare products and go on to use them as found in the study by Muise and Desmarais (2010), it is not impossible that there are women who perceive all 'whitevertised' skincare products as unsafe and still go on to patronize them.

From the health perspective, it seems the mass media has not been used to disseminate the health risks 'whitevertised' skincare products can pose as much as it has been used to market the beauty standard. Findings from this study show that while majority of the respondents have seen an advertisement for a whitening skincare product, majority of them have low awareness on the health risks they can pose. The evidence that the number of respondents who stated 'family and friends' as their source of awareness on the health risks of 'whitevertised' skincare products is greater than the total of all those who stated the mass media as theirs substantiates the assertion that the mass media has been used more for marketing whitening skincare products than disseminating information on their health risks. This could be the reason for the low level of risk awareness among majority of the respondents, considering the importance of the mass media in creating health awareness.

\section{CONCLUSION}

The white beauty hegemony seems strengthened by the media's portrayal of a white beauty standard (through 'whitevertising', which is shown in this study to be rampant) on the one hand, and the African woman's reverence for 'white skin' on the other. However, this study showed that the potential impact of advertising for whitening skincare products in a society where white skin is revered is still filtered by consumer perception. The perception theory, which underpinned this study, helped explain how Nigerian women, although exposed to 'whitevertised' skincare products, could perceive them in different ways, culminating in either negative or positive perception.

From the findings of this study, it is apparent that women in Anambra State have positive perception toward some 'whitevertised' skincare products and negative perception toward others. Such factors that could influence this perception as price, use of celebrities in advertisement, the experience of side effects, scientification, and product's place of origin helped explain why this is so. For instance, most of the women are likely to choose the expensive and foreign-made 'whitevertised' skincare products over the others because they perceive them as being of good quality. Though most of the women seemed to perceive 'whitevertised' skincare products as unsafe generally- a perception that could be described as negative- these factors helped explain why they could still go for these products. This finding in some way countered the view of Danijela, Slobodan, Vesna, Dragan, Danijela,Brankic 
and Milijasevic(2011) that for consumers to purchase and consume a product willingly, their perception has to be positive towards it. Not just this result but the assertion of Koster and Mojet (2007) does the same. For these scholars, perception is not fixed but dynamic and there are often differences between what consumers perceive and their behaviour. Findings from this study showed that despite the women's negative perception towards these products,regarding safety, they were likely to go for the foreign-made and expensive ones perceived to be of good quality. It can as well be a case of perceived benefit outweighing perceived risk just as Yoo and Kim (2012) also found. For the scholars, even if risk is perceived, the benefit perceived is greater for consumers who want to maintain a certain appearance.

This study argues that the Nigerian woman can be swayed by advertisements for whitening skincare products once the products are presented as foreign, celebrity-endorsed, scientifically tested, and expensive, and her susceptibility to the persuasive effects of these gimmicks is due her continuous exposure to a universal beauty standard which highlights 'white' as ideal. Regarding audience awareness on the health risks of these products, it is surprising that the younger audience with all the information the Internet and other media are supposed to avail them, showed a low level of awareness. In addition, the women's perception of these products as safe may not only be due to their carefreeness as findings from TNS Opinion \& Social (2009) show but also their low level of health risk awareness. As shown in this study, low level of health risk awareness translated to the perception of some of these products as safe.

This study also argues that the reason for the low level of awareness among most of the respondents is due to the seeming non-use of mass media for the dissemination of information on the health risks of 'whitevertised' skincare products. The mass media seem to have been more a means for the marketing of these products than for disseminating information on the health risks they can pose. This study has shown that most Nigerian women are exposed to 'whitevertised' skincare products and perceive majority of them as capable of producing a whitening effect, desirable and safe to use. It has also shown that most women are unaware of the serious health risks posed by these products.

The tendency of women to have positive perception toward 'whitevertised' skincare products based on such factors as price, place of origin, use of celebrities in advertising, and scientification; search, purchase and use these products to achieve a desired whitening effect, and the possibility that they are unaware of their health risks make it salient for planned action. This planned action which can come in the form of audio/ visual messages, or both, can be targeted since it is clear from the findings the category of women who are more vulnerable- the young and those lacking formal education.

\section{RECOMMENDATIONS}

The following recommendations are made based on the findings of this study:

1. Agencies like the Broadcasting Organization of Nigeria and Standards Organization of Nigeria should look into advert claims made by manufacturers of whitening skincare products to ensure they are consistent with what the products can avail consumers. Advertisements found to be exaggerative or deceptive should be banned.

2. Government and non-governmental health bodies should organize health awarenes campaigns on the health risk of whitening skincare products to dissuade women (mostly th 
DOI: doi.org/10.47851/naujocommed.v2i1.117

young and those with little or no formal education) from patronizing them. These campaigns should also be designed in local languages to enhance their effectiveness among the rural populace and those with little or no formal education.

\section{REFERENCES}

Adow, M. (2013).Nigeria's dangerous skin whitening obsession.Retrieved August 12, 2016 fromhttp://www.aljazeera.com/indepth/2013/04/20134514845907984.html

Ahmed, R.R., Seedani, S.K., Ahuja, M.K., \&Paryani, K. (2015). Impact of celebrity endorsement on consumer buying behavior. SSRN, 16, 12-20

Armenian Women for Health and Healthy Environment (2011).Case study on Mercury in skin lightening creams in EECCA, in particular in Armenia, Belarus and Georgia. Retrieved August 11 , 2016 fromhttp://www.zeromercury.org/..._Armenia/19_04_2011_Case_Study_Cosmetics_ EECCA

Arif, H. (2004). Woman's body as a color measuring text: a signification of Bengali culture. Semiotica, 150(1/4), 579-595

Charles, C.A.D (2003). Skin-bleaching, self-hate, and black identity in Jamaica.Journal of Black Studies, 33(6), 711-728

Cristaudo, A., D’illio, S., Gallinella, B., Mosca, A., Majorani, C., Violante, N., Senofonte, O.,

Morrone, A., \&Petrucci, F. (2013). Use of potentially harmful skin-lightening products among immigrant women in Rome, Italy: a pilot study. Dermatology, 226 (3), 200206

Danijela, S., Slobodan, L., Vesna, D., Dragan, M., Danijela,V., Brankica, L., \&Milijasevic, M. (2011). The role of consumer's perception in purchasing of meat and meat products. $5^{\text {th }}$ International Meat Industry Conference, Book of Abstracts, page 161

De Cort, A. (2009). The ideal of female beauty in two different cultures: socio-cultural analysis of Belgian and Malaysian print advertisements. Novitas-ROYAL, 3(2), 117128

Etcoff, N., Orbach, S., Scott, J., \& D’ Agostino, H. (2004).The real truth about beauty: a global report. Retrieved September14, 2015 from http://www.campaignforrealbeauty.ca/uploadedFiles/dove_white_paper_final.pdf>

Ibenegbu, G. (2018). The biggest market in Africa. Retrieved April 12, 2016 from https://www.legit.ng/1154853-the-biggest-market-africa.html

Koster, E.P., \&Mojet, J. (2007).Theories of food choice development.In L. Frewer\& H.C.M. Van Trijp (Eds), Understanding consumers of food products (pp.93-124). Abbington, Cambridge, UK: Woodhead Publishing

Kuffour, R.A., Dartey, E., Owusu, W., \&Dabouh, P.M. (2014). Level of awareness of effec 
of the use of cosmetic bleaching products among women: a case study of Bolgatanga municipality of Ghana. Research on Humanities and Social Sciences, 4(11), 57-62

Ladizinski, B., Mistry, N., \&Kundu, R.V. (2011). Widespread use of toxic skin lightening compounds: medical and psychosocial aspects. Dermatologic Clinics, 29, 111-123

Leong, S. (2006). Who's the fairest of them all? Television ads for skin-whitening cosmetics in Hong Kong.Asian Ethnicity, 7(2),167-181

McDougall, A. (2013). Skin whitening products have global potential if marketed correctly. Retrieved August 12, 2018 from https://www.cosmeticsdesign-asia.com/MarketTrends/Skin-whitening-products-have-global-potential-IF-marketed-correctly.

McQuail, D. (2010).Mass communication theory ( $6^{\text {th }}$ edition). London: Sage Publications.

Muise, A., \&Desmarais, S. (2010). Women's perceptions and use of 'anti-aging' products.Sex Roles, 63(1), 126-137

Mire, A. (2005).Pigmentation and empire: the emerging skin-whitening industry. Retrieved October 16, 2016 from http://www/counterpunch.org

Murphy, T., Kim, S., Chanra, P., Lim, S., Wilson, K., Irvine, K.N., Slotton, D.G., \& Allen, L.(2015). Mercury contamination of skin-whitening creams in Phnom Penh, Cambodia.Journal of Health and Pollution, 5(9), 33-46

Okunna, C.S., \&Omenugha, K.A. (2012).Introduction to mass communication ( $3^{\text {rd }}$ Ed.). Enugu: New Generation Books.

Olumide, Y.M., Akinkugbe, A.O., Altraide, D., Mohammed, T., Ahamefule, N., Ayanlowo, S.,Onyekonwu, C., \& Essen, N. (2008).Complications of chronic use of skin lightening cosmetics.International Journal of Dermatology, 47(4), 344-353

Santoso, T., \&Raharjo, L. (2013). Natural and organic skin care perception: a study in Jakarta. International Conference on Entrepreneurship and Business Management

Saeed, R., Naseer, R., Haider, S., \&Naz, U. (2014). Impact of celebrity and non-celebrity advertisement on consumer perception. The Business and Management Review, 4(3), 154-160

Sokal, A., \&Bricmont, J. (1999).Fashionable nonsense: postmodern intellectuals' abuse of science. New York: Picador.

Street, J.C., Gaska., K., Lewis, K.M., \& Wilson, M.L. (2014). Skin bleaching: A neglected form of injury and threat to global skin. African Safety Promotion: A Journal of Injury and Violence Prevention, 12(1)

Sylvia, K. (2014). Hegemonic whiteness: A qualitative study of fairness advertisements in India: Texas State Undergraduate Research Journal, 2(1), 1-5 
DOI: doi.org/10.47851/naujocommed.v2i1.117

Thanisorn, R., Byaporn, N., \&Chanchai, B. (2012). Thai consumers' perception on herbal cosmetic products: a comparative study of Thai and imported products. Information Management \& Business Review, 4(1), 35-40

TNS Opinion \& Social.(2009). Europeans' attitudes toward chemicals in consumer products: Risk perception of potential health hazards. Special Eurobarometer314/71.1

UNEP.(2008).Mercury in products and wastes. Geneva, United Nations Environment Programme, Division of Technology, Industry and Economics, Chemical $\begin{array}{lll}\text { Branch.Retrieved June 17, } 2015 & 2015\end{array}$ fromhttp://www.unep.org/chemicalsandwaste/portals/9/Mercury/AwarenessPack/Engl ish/UNEP_Mod1_UK_Web.pdf

World Health Organization.(2011). Preventing disease through healthy environments. Mercury in skin lightening products. Retrieved January 12, 2016 from http://www.who.int/ipcs/assessment/public_health/mercury_flyer.pdf

Yoo, J-J., Kim, H-Y. (2012). Perceived risk of sunless tanning product use and its relationship to body satisfaction. International Journal of Marketing Studies, 4(4), 13 21

Zhang, L. (2013). Eurocentric beauty ideals as a form of structural violence: origins and effects on east Asian women. Retrieved March 10,2015 from http://twp.duke.edu/uploads/media_items/leizhang-delib2013.original.pdf 